\title{
Surgical treatment of advanced penile cancer
}

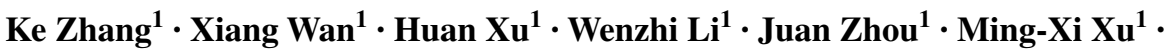 \\ Hai-Jun Yao ${ }^{1} \cdot$ Zhong Wang $^{1}$
}

Received: 22 January 2017 / Accepted: 5 May 2017 / Published online: 10 May 2017

(c) The Author(s) 2017. This article is an open access publication

\begin{abstract}
Purpose To evaluate the therapeutic effect of surgery in patients with advanced penile cancer, who have a dismal prognosis.

Patients and methods Between September 2007 and July 2015, we treated 12 patients with surgical therapy.

Results The median follow-up period for all the patients was 16 months (range 4-60 months). The outcome and concomitant symptoms were analyzed, and the survival rates were calculated. Three of the patients are currently alive. The median overall survival of the patients was 9 months (range 4-13 months).

Conclusion The present results suggest that surgery is a valuable treatment option for patients with advanced penile cancer. The prognosis of advanced penile cancer is closely related to lymph node and distant metastases. Flap repair can solve the problem of large area skin defect. Advanced penile cancer is difficult to treat regardless of chemotherapy or radiotherapy, and surgery cannot prolong the lives of patients. However, the dissection of lesions and repair of large area skin defects can dramatically improve the quality of life of patients, especially those with locally advanced disease without distant metastasis.
\end{abstract}

Ke Zhang and Xiang Wan contributed equally.

Hai-Jun Yao

dryaohj@163.com

Zhong Wang

zhongwang2010@sina.com

1 Department of Urology, Shanghai Ninth People's Hospital, Shanghai Jiao Tong University School of Medicine, No.639 of Zhizaoju Road in Huangpu District, Shanghai 200011, China
Keywords Advanced · Penile cancer · Therapy · Surgery

\section{Introduction}

Penile cancer (PC) is an uncommon malignant tumor, with around 4000 cases diagnosed each year, accounting for less than $0.5 \%$ of all cancers (Mosconi et al. 2005). It is rare in Western countries, but not in developing countries (Micali et al. 2006). Unfortunately, its incidence continues to increase in parts of Asia, Africa, and South America (Ornellas 2008; Misra et al. 2004), but decreased in the United States from 1973 to 2002. In 2012, 1570 new cases and 370 deaths were documented in America (Siegel et al. 2012; Barnholtz-Sloan et al. 2007). In less developed nations, the condition is even worse, such as in sub-Saharan Africa and parts of South America, where it accounts for around $10 \%$ of all male malignancies (Heinlen et al. 2012).

The focus of this article is advanced penile cancer which can be defined as bulky lymph node metastases ( $\mathrm{cN} 2$ or $\mathrm{cN} 3$ ), failed primary lymphadenectomy leading progression to nodal metastases, matted or bulky lymphadenopathy (cN3), 2 metastatic superficial and deep inguinal lymph nodes (pN2), metastatic pelvic lymph node (N3), local erosion to pubic bone, abdominal wall, or pelvis (T4), and distant metastases (M1) (Heinlen et al. 2012).

The current therapies for advanced penile carcinoma include surgical therapy, radiotherapy, chemotherapy, or multimodality therapy (Heinlen et al. 2012). The prognosis in advanced penile carcinoma is poor, especially in patients with more than 2 inguinal lymph node metastases. The 5-year survival rate of these patients is $7-50 \%$. Mortality markedly increases when pelvic lymph node metastasis develops, which means a 5-year survival of $<5 \%$ (Srinivas et al. 1987; Ravi 1993). We report our experience of using 
Table 1 Surgery and adjuvant therapy of 12 patients

\begin{tabular}{llll}
\hline Patients & Surgery on penis & Using ALT flap & Adjuvant therapy postoperatively \\
\hline 1 & Total penile resection & Yes & No \\
2 & Total penile resection & Yes & No \\
3 & Partial penectomy & No & No \\
4 & Total penile resection & No & No \\
5 & Total penile resection & Yes & No \\
6 & Total penile resection & No & No \\
7 & Partial penectomy & No & Chemotherapy + radiation \\
8 & Total penile resection & No & No \\
9 & Partial penectomy & No & No \\
10 & Total penile resection & No & Chemotherapy \\
11 & Partial penectomy & No & No \\
12 & Partial penectomy & Yes & No \\
\hline
\end{tabular}

surgical treatment in the management of patients with advanced penile cancer.

\section{Patients and methods}

After Institutional Review Board (IRB) approval, we identified 12 patients who underwent surgical treatment for advanced penile cancer at our hospital. We retrospectively evaluated these patients who were treated between September 2007 and July 2015 in our hospital and followed up until December 2015. Five patients had ECOG performance status 2; five patients had ECOG performance status 3; two patients had ECOG performance status 4 before the operation.

All of the 12 patients received partial penectomy or radical penectomy with inguinal lymph node dissection (Table 1). Patients of No. 1, 2, 5, 12 received abdominal wall defect repair and skin grafting because of the large area skin defects (Figs. 1, 2, 3). Two patients received postoperative chemotherapy (ifosfamide, paclitaxel, and cisplatin), and one patient received radiotherapy (50 Gy).

\section{Results}

The median patient age was 54.6 years (range $37-89$ years). The clinical data of the patients are summarized in Table 2. The flap of the three patients with large area defects healed well (Fig. 4) and one patient delayed healing, two patients experienced edema of lower extremity. No severe complications occurred during hospitalization and 10 of 12 patients thought their dysuria, pain ameliorated, quality of life improved dramatically and the surgery rewarding. All the 12 patients were followed up 16 months on average (range 4-60 months), three patients are currently alive, and the other nine patients died (mortality, 75\%)

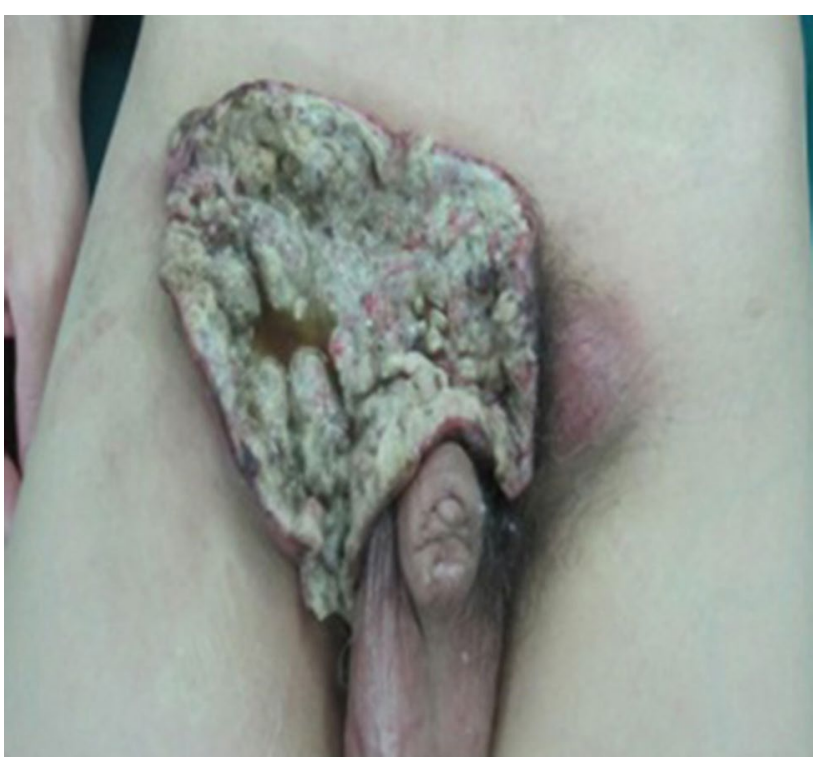

Fig. 1 Tumor invades the right inguinal region, skin erosion with pain

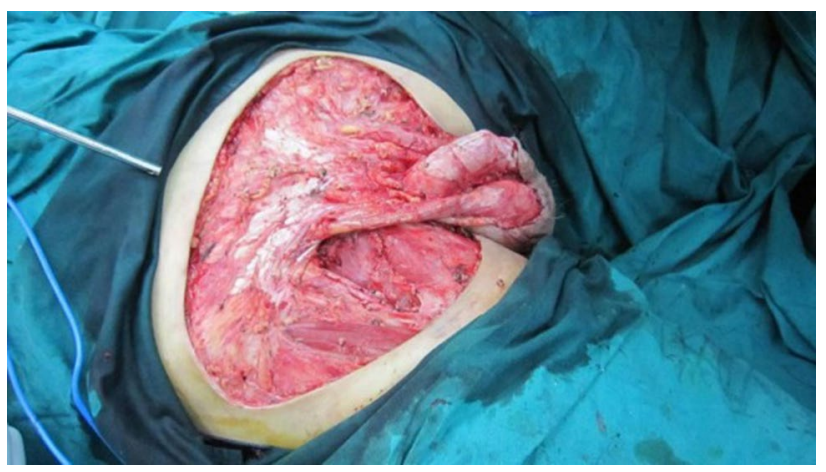

Fig. 2 The defect after the tumor resection 
Table 2 Clinical characteristics of 12 patients with advanced penile cancer

\begin{tabular}{|c|c|c|c|c|c|c|c|c|c|}
\hline Patients & Age & Grade & Stage & $\begin{array}{l}\text { Tumor size } \\
(\mathrm{cm})\end{array}$ & $\begin{array}{l}\text { Lymph node } \\
\text { metastasis }\end{array}$ & $\begin{array}{l}\text { Distant metas- } \\
\text { tasis }\end{array}$ & $\begin{array}{l}\text { Concomitant } \\
\text { symptoms }\end{array}$ & $\begin{array}{l}\text { Symptom } \\
\text { improve? }\end{array}$ & Survival (month) \\
\hline 1 & 37 & $\mathrm{G} 2 / 3$ & T4NOMO & $20 \times 20$ & No & No & Dysuria & Yes & 12 \\
\hline 2 & 67 & G2 & T4NOMO & $10 \times 12$ & No & No & Dysuria & Yes & Alive (60) \\
\hline 3 & 89 & G2 & $\mathrm{T} 2 \mathrm{~N} 3 \mathrm{M} 1$ & $4 \times 4$ & $\begin{array}{l}\text { Bilateral } \\
\text { inguinal } \\
\text { region + pel- } \\
\text { vic capacity }\end{array}$ & Lung & Pain & Yes & 10 \\
\hline 4 & 55 & $\mathrm{G} 2 / 3$ & $\mathrm{~T} 2 \mathrm{~N} 3 \mathrm{M} 0$ & $4 \times 3$ & $\begin{array}{l}\text { Bilateral ingui- } \\
\text { nal }\end{array}$ & No & No & No & 4 \\
\hline 5 & 40 & G1 & T4N0M0 & $8 \times 15$ & No & No & Dysuria & Yes & Alive (31) \\
\hline 6 & 43 & $\mathrm{G} 1 / 2$ & T3N3M0 & $6 \times 4$ & $\begin{array}{l}\text { Bilateral } \\
\text { inguinal } \\
\text { region }+ \text { pel- } \\
\text { vic capacity }\end{array}$ & No & Dysuria & Yes & 11 \\
\hline 7 & 52 & G1 & T4N2M0 & $8 \times 12$ & $\begin{array}{l}\text { Bilateral ingui- } \\
\text { nal }\end{array}$ & No & Pain & Yes & Alive (18) \\
\hline 8 & 50 & $\mathrm{G} 2$ & T4N2M1 & $8 \times 10$ & $\begin{array}{l}\text { Bilateral ingui- } \\
\text { nal }\end{array}$ & Lumbar & No & No & 9 \\
\hline 9 & 47 & G3 & T4N3M1 & $9 \times 10$ & $\begin{array}{l}\text { Bilateral } \\
\text { inguinal } \\
\text { region + pel- } \\
\text { vic capacity }\end{array}$ & Lung & Dysuria & Yes & 5 \\
\hline 10 & 60 & $\mathrm{G} 2 / 3$ & T3N2M1 & $7 \times 4$ & $\begin{array}{l}\text { Bilateral ingui- } \\
\text { nal region }\end{array}$ & Lung & Dysuria & Yes & 6 \\
\hline 11 & 67 & G2 & $\mathrm{T} 2 \mathrm{~N} 3 \mathrm{M} 0$ & $4 \times 4$ & $\begin{array}{l}\text { Right side } \\
\text { inguinal } \\
\text { region + pel- } \\
\text { vic capacity }\end{array}$ & No & Pain & Yes & 5 \\
\hline 12 & 48 & $\mathrm{G} 1 / 2$ & $\mathrm{~T} 2 \mathrm{~N} 3 \mathrm{M} 0$ & $15 \times 12$ & $\begin{array}{l}\text { Right side } \\
\text { inguinal } \\
\text { region }\end{array}$ & No & Pain & Yes & 13 \\
\hline
\end{tabular}

because of the progression of the original disease or distant metastases. The mean time from operation to death was 9 months (range 4-13 months). Three of the four patients with regional advanced PC without distant metastasis are currently alive, with 60 months as the longest period. We offer the palliative care to assess the multifaceted needs of patients to help them combat issues of pain, constipation, psychological and cognitive effects.

\section{Discussion}

Treatment for advanced PC is still a worldwide problem, as the ideal prognosis of patients has not been achieved. The effects of radiotherapy and chemotherapy are not good. Radiotherapy can be performed as a single agent, but its usefulness is questionable. While data are scant, existing evidence shows the efficacy of chemotherapy for this disease. Administration of chemotherapy in addition to surgery or radiotherapy may increase patient survival

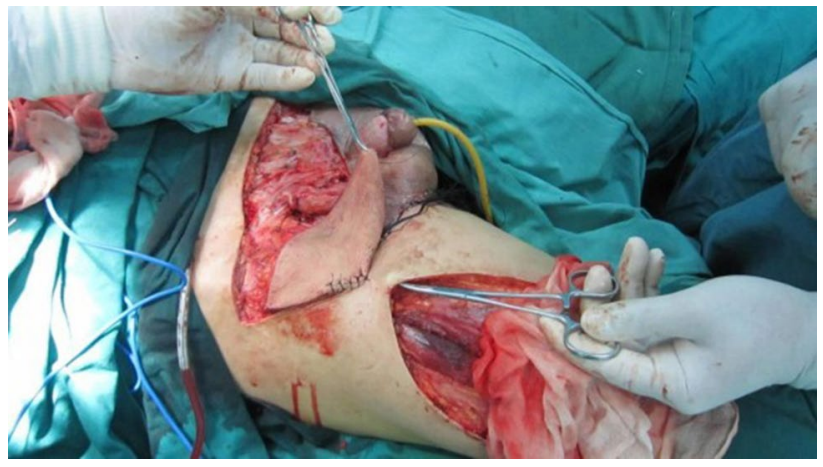

Fig. 3 We use right side of the lateral femoral circumflex perforator flaps cover the defect

(Heinlen et al. 2012). However, no consensus has been reached as to the significant efficacy of chemotherapy or multimodality therapy for advanced penile carcinoma or metastatic PC. New effective drugs should be developed, and multicenter cooperation is essential. 


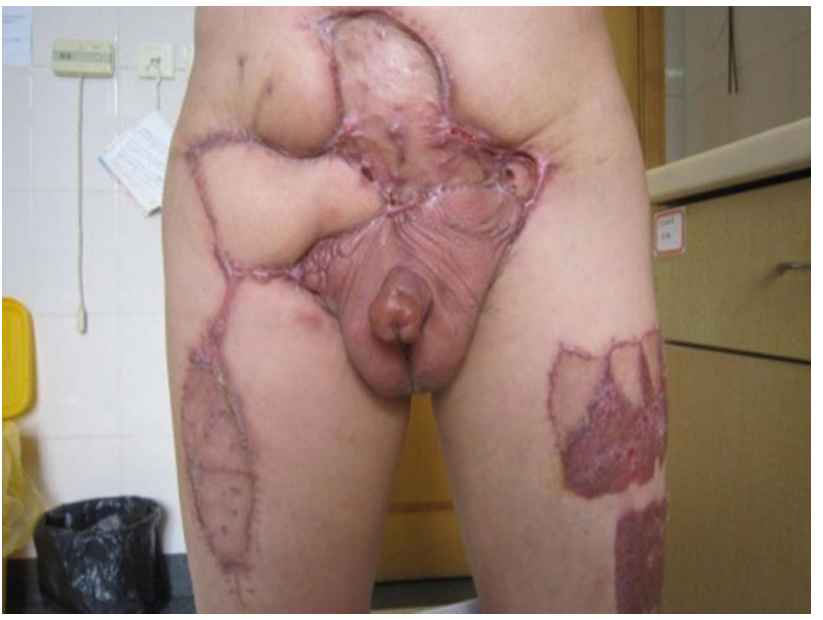

Fig. 4 Flap and donor site healing well 3 months after the operation

Advanced PC is associated with poor prognosis and is closely related to lymph node metastasis. The more lymph node metastases found, the worse the condition. Pandey et al. (2006) evaluated 102 patients with inguinal lymph node. Patients with $1-3,4$ or 5 , or $>5$ lymph nodes involved have a $75.6,8.4$, or $0 \% 5$-year survival rate, respectively. According to Yao Zhu et al. (2012), unilateral and bilateral lymph node metastases have 3-year recurrence-free survival rates of 59.2 and $26.7 \%$, respectively. Much evidence has proven that the ratio of positive lymph nodes have more advantage than number-based nodal staging in predicting cancer prognosis (Vinh-Hung et al. 2009a, b; Berger et al. 2005). According to Svatek et al. (2009), the 5-year disease-specific survival rates in patients with lymph node ratios of $<6.7$ and $>6.7 \%$ are 91.7 and $23.3 \%$, respectively, which indicates a statistically significant difference. Pelvic lymph node involvement is an independent poor prognostic factor. Pandey et al. reported that none of their 21 patients with pelvic lymph nodes survived for even at least $>3$ years. Similar findings were reported by Ravi (1993). According to Zhu et al. (2012), patients with sentinel lymph nodes of $<2$ and $>2 \mathrm{~mm}$ in size had disease-specific survival rates of 94.4 and $69.5 \%$, respectively. The size of the sentinel lymph node can predict additional lymph node metastasis, but this needs further study. Among our 12 patients, 6 with N3 stage disease died with a 7.4-month survival on average. Their prognosis was poor, consistent with a previous report in the literature (Zhu and Ye 2012).

Obviously, distant metastasis is an important factor that affects prognosis. According to Bermejo et al. (2007), in their study, one patient with lung metastases who underwent BMP (bleomycin-methotrexate-cisplatin) chemotherapy only survived 7 months. Another patient had liver and lung metastases after 5 months of BMP treatment and died 2 months later. According to
Carthon et al. (2014), 14 patients with distant metastases (M1) received epidermal growth factor receptortargeted therapy, with a mean overall survival period of 264 days (range 31-1332 days). According to Di Lorenzo et al. (2009), three patients with distant metastases that included liver, lung, or abdominal lymph nodes had a median overall survival of 8 months. All of the four patients with distant metastases (3 lung metastasis and 1 lumbar vertebrae metastasis) died, with a mean survival of 7.5 months (range 5-10 months).

Patients with locally advanced disease without distant metastasis and N3 lymph node metastasis have a relatively long survival. Four of the 12 patients had T4N12M0 stage disease, 3 of whom are currently alive, but 1 died after 12 months. The longest survival period was $>5$ years. We should perform radical surgery for patients with partial advanced PC without clear metastasis if their physical conditions permit. For the seventh $\mathrm{N}$ category, the 3-year recurrence-free survival rates of N1, N2, and N3 were $87.5 \%(n=16), 57 \%(n=22)$, and $31.8 \%(n=22)$, respectively (Zhu and Ye 2012). According to Liu et al. (2013), patients with T0-3N0-2M0 disease have an overall survival of $>14$ months, and the longest surviving patient is still alive up to now.

Some scholars put forward multimodality therapy according to the poor effect of the treatment of advanced PC. According to Komine et al. (2014), a patient (80-yearold, pT1pN0) who underwent penectomy and bilateral inguinal lymphadenectomy had a disease relapse after 1 year. He was treated with TPF (paclitaxel-cisplatin5-FU) chemotherapy and 50-Gy external beam radiotherapy to the inguinal region, along with Mohs' paste. For socioeconomic reasons, the patient canceled his treatment and showed no progression or metastasis after 8 months, but died after 12 months. According to Pagliaro et al. (2009), preoperative (neoadjuvant) combination chemotherapy can dramatically improve the progression-free survival of patients with lymph node metastases. Postoperative radiotherapy can be performed depending on the amount of residual disease. Chemoradiotherapy has been proven effective for unresectable PC. However, the number of cases treated with multimodalities is too small. No consensus has been reached as to the appropriate approach for multimodality therapy for advanced PC.

Although advanced PC is associated with poor prognosis, surgical treatment is still a relatively effective approach. Most of our 12 patients had dysuria or pain. Some of them had a large wound erosion area, which affected their quality of life. For these patients, control of local and systemic disease is the goal of treatment (Heinlen et al. 2012). All the 12 patients received surgical therapy, including partial penectomy or radical penile dissection and inguinal lymph node dissection, and 1 
pelvic lymph node dissection. Our follow-up indicated that the postoperative symptom of dysuria and pain in these patients greatly improved.

Flap repair can solve the problem of skin defect after penectomy. Kayes et al. (2007) performed vertical rectus abdominis flap reconstruction in patients with advanced PC in 2007 and yielding a satisfying outcome. We performed thigh myocutaneous flap reconstruction or largesized skin graft for four cases with large skin defects. The effect of the use of a myocutaneous flap was better because of abundant blood supply. It allowed for faster healing and reduced the risk of infection. The complete free flap has limited blood supply; thus, the healing time is longer. However, it is advantageous for surgical trauma. The flap can be chosen according to skin defect size, and physical and skin conditions. The four patients received a skin graft or flap reconstruction, and healed well and had greatly improved quality of life.

NCCN recommended $\mathrm{T} \geq 2$ patients require more extensive surgical intervention with partial or total penectomy to remove the lesions; Patients with palpable nodes advised standard or modified ILND (inguinal lymph node dissection); Patients with 2 or more positive ILNs (inguinal lymph node), poorly differentiated metastases, or extracapsular nodal extension are recommended to PLND (pelvic lymph node dissection) (Clark et al. 2013). We evaluated the age, physical status, primary tumor, inguinal lymph node metastases, and pelvic lymph node metastases of the 12 patients. We recommended neoadjuvant followed by surgical treatment, but for certain reasons they refused, so we performed surgery for them. All the 12 patients considered physical functioning, role functioning, emotional functioning, cognitive functioning, and social functioning improved significantly and deem the surgery rewarding. In addition to 1 flap delayed healing and 2 edema of lower extremity, all patients felt their symptoms alleviated allowing them a reasonable quality of life. No severe complications occurred postoperatively. So we think that we relieved their pain and improved their quality of life.

The low incidence and dispersed data of PC led to the lack of systematic comparison data. In addition, the classic paradigm of randomized trials may be difficult to execute for this rare malignancy (Sonpavde et al. 2013). The few reported cases led to data bias. All our 12 patients received surgical therapy. However, we could not compare our patients to those who did not undergo surgery because of the lack of detailed nonsurgical treatment data. Thus, we rely on foundations or international organizations for PC, like other cancers, to promote the communication and research between physicians to help patients with advanced PC. Moreover, a specific and detailed questionnaire should be developed to assessing quality of life for penile cancer.

\section{Conclusion}

Advanced PC is difficult to treat regardless of chemotherapy or radiotherapy, and surgery cannot prolong the lives of patients. However, dissection of lesions and repair of large area skin defects can dramatically improve quality of life, especially, that of patients with locally advanced disease without distant metastasis. We recommend multimodality therapy, but in some cases surgery could be performed firstly to improve quality of life.

Acknowledgements The work was sponsored by the National Natural Science Foundation of China (Grant No. 81172450, 81202008, 81402089), Pudong Health and Family Planning commission (PWZxq2014-11, PW2013D-3), Program for Outstanding Medical Academic Leader. The foundation of Shanghai Science and Technology committee (Grant No. 134119a9800).

Author contributions KZ participated in the data analysis and drafted the manuscript. XW carried out the writing and performed the statistical analysis. HX participated in the revision and WL participated in the data collection, JZ carried out the editorial support for this manuscript, ZW, M-XX, H-JY conceived of the study, and participated in its design and coordination and helped to draft the manuscript. All authors read and approved the final manuscript.

\section{Compliance with ethical standards}

Funding The work was sponsored by the National Natural Science Foundation of China (Grant No. 81172450, 81202008, 81402089), Pudong Health and Family Planning Commission (PWZxq2014-11, PW2013D-3), The foundation of Shanghai Science and Technology committee (Grant Nos. 134119a9800).

Conflict of interest We have no conflict of interest to declare.

Ethical approval This article does not contain any studies with human participants or animals performed by any of the authors.

Open Access This article is distributed under the terms of the Creative Commons Attribution 4.0 International License (http://creativecommons.org/licenses/by/4.0/), which permits unrestricted use, distribution, and reproduction in any medium, provided you give appropriate credit to the original author(s) and the source, provide a link to the Creative Commons license, and indicate if changes were made.

\section{References}

Barnholtz-Sloan JS, Maldonado JL, Pow-sang J, Giuliano AR (2007) Incidence trends in primary malignant penile cancer. Urol Oncol 25:361-367. doi:10.1016/j.urolonc.2006.08.029

Berger AC, Sigurdson ER, LeVoyer T, Hanlon A, Mayer RJ, Macdonald JS, Catalano PJ, Haller DG (2005) Colon cancer survival is associated with decreasing ratio of metastatic to examined lymph nodes. J Clin Oncol 23:8706-8712. doi:10.1200/ JCO.2005.02.8852 
Bermejo C, Busby JE, Spiess PE, Heller L, Pagliaro LC, Pettaway CA (2007) Neoadjuvant chemotherapy followed by aggressive surgical consolidation for metastatic penile squamous cell carcinoma. J Urol 177:1335-1338. doi:10.1016/j. juro.2006.11.038

Carthon BC, Ng CS, Pettaway CA, Pagliaro LC (2014) Epidermal growth factor receptor-targeted therapy in locally advanced or metastatic squamous cell carcinoma of the penis. BJU Int 113:871-877. doi:10.1111/bju. 12450

Clark PE, Spiess PE, Agarwal N, Biagioli MC, Eisenberger MA, Greenberg RE, Herr HW, Inman BA, Kuban DA, Kuzel TM, Lele SM, Michalski J, Pagliaro L, Pal SK, Patterson A, Plimack ER, Pohar KS, Porter MP, Richie JP, Sexton WJ, Shipley WU, Small EJ, Trump DL, Wile G, Wilson TG, Dwyer M, Ho M (2013) Penile cancer: clinical practice guidelines in oncology. J Natl Compr Cancer Netw 11:594-615

Di Lorenzo G, Cartenì G, Autorino R, Gonnella A, Perdonà S, Ferro M, Longo N, Rescigno P, Doria F, Faiella A, Altieri V, Palmieri G, Imbimbo C, Mirone V, De Placido S (2009) Activity and toxicity of paclitaxel in pretreated metastatic penile cancer patients. Anticancer Drugs 20:277-280. doi:10.1097/ CAD.0b013e328329a293

Heinlen JE, Buethe DD, Culkin DJ (2012) Advanced penile cancer. Int Urol Nephrol 44:139-148. doi:10.1007/s11255-011-0011-1

Kayes OJ, Durrant CA, Ralph D, Floyd D, Withey S, Minhas S (2007) Vertical rectus abdominis flap reconstruction in patients with advanced penile squamous cell carcinoma. BJU Int 99:37-40. doi:10.1111/j.1464-410X.2007.06582.x

Komine N, Narita S, Kigure T, Tsuruta H, Numakura K, Akihama S, Saito M, Inoue T, Tsuchiya N, Satoh S, Nanjo H, Habuchi $T$ (2014) Successful local control of recurrent penile cancer treated with a combination of systemic chemotherapy, irradiation, and mohs' paste: a case report. Case Rep Oncol 7:522-527. doi: $10.1159 / 000365809$

Liu JY, Li YH, Liu ZW, Zhang ZL, Ye YL, Yao K, Han H, Qin ZK, Zhou FJ (2013) Intraarterial chemotherapy with gemcitabine and cisplatin in locally advanced or recurrent penile squamous cell carcinoma. Chin J Cancer 32:619-623. doi:10.5732/ cjc. 012.10275

Micali G, Nasca MR, Innocenzi D, Schwartz RA (2006) Penile cancer. J Am Acad Dermatol 54:369-391. doi:10.1016/j. jaad.2005.05.007

Misra S, Chaturvedi A, Misra NC (2004) Penile carcinoma: a challenge for the developing world. Lancet Oncol 5:240-247. doi:10.1016/S1470-2045(04)01427-5
Mosconi AM, Roila F, Gatta G, Theodore C (2005) Cancer of the penis. Crit Rev Oncol Hematol 53:165-177. doi:10.1016/j. critrevonc.2004.09.006

Ornellas AA (2008) Management of penile cancer. J Surg Oncol 97:199-200. doi:10.1002/jso.20893

Pagliaro LC, Crook J (2009) Multimodality therapy in penile cancer: when and which treatments? World J Urol 27:221-225. doi:10.1007/s00345-008-0310-z

Pandey D, Mahajan V, Kannan RR (2006) Prognostic factors in nodepositive carcinoma of the penis. J Surg Oncol 93:133-138. doi: $10.1002 /$ jso. 20414

Ravi R (1993) Correlation between the extent of nodal involvement and survival following groin dissection for carcinoma of the penis. Br J Urol 72:817-819

Siegel R, Naishadham D, Jemal A (2012) Cancer statistics 2012. CA Cancer J Clin 62:10-29. doi:10.3322/caac.20138

Sonpavde G, Pagliaro LC, Buonerba C, Dorff TB, Lee RJ, Di Lorenzo G (2013) Penile cancer: current therapy and future directions. Ann Oncol 24:1179-1189. doi:10.1093/annonc/mds635

Srinivas V, Morse MJ, Herr HW, Sogani PC, Whitmore WF Jr (1987) Penile cancer: relation of extent of nodal metastasis to survival. J Urol 137:880-882

Svatek RS, Munsell M, Kincaid JM, Hegarty P, Slaton JW, Busby JE, Gaston KE, Spiess PE, Pagliaro LC, Tamboli P, Pettaway CA (2009) Association between lymph node density and disease specific survival in patients with penile cancer. J Urol 182:27212727. doi:10.1016/j.juro.2009.08.029

Vinh-Hung V, Nguyen NP, Cserni G, Truong P, Woodward W, Verkooijen HM, Promish D, Ueno NT, Tai P, Nieto Y, Joseph S, Janni W, Vicini F, Royce M, Storme G, Wallace AM, Vlastos G, Bouchardy C, Hortobagyi GN (2009a) Prognostic value of nodal ratios in node-positive breast cancer: a compiled update. Future Oncol 5:1585-1603. doi:10.2217/fon.09.129

Vinh-Hung V, Verkooijen HM, Fioretta G, Neyroud-Caspar I, Rapiti E, Vlastos G, Deglise C, Usel M, Lutz JM, Bouchardy C (2009b) Lymph node ratio as an alternative to $\mathrm{pN}$ staging in node-positive breast cancer. J Clin Oncol 27:1062-1068. doi:10.1200/ JCO.2008.18.6965

Zhu Y, Ye DW (2012) Lymph node metastases and prognosis in penile cancer. Chin J Cancer Res 24:90-96. doi:10.1007/ s11670-012-0090-2 